\title{
Review Article \\ The Role of TLR2, TLR4, and TLR9 in the Pathogenesis of Atherosclerosis
}

\author{
Mohsin H. K. Roshan, Amos Tambo, and Nikolai P. Pace \\ Department of Anatomy, Faculty of Medicine and Surgery, University of Malta, Msida, Malta \\ Correspondence should be addressed to Mohsin H. K. Roshan; mohsin.roshan.13@um.edu.mt
}

Received 17 July 2016; Revised 5 September 2016; Accepted 15 September 2016

Academic Editor: Jean-Marc Cavaillon

Copyright ( 2016 Mohsin H. K. Roshan et al. This is an open access article distributed under the Creative Commons Attribution License, which permits unrestricted use, distribution, and reproduction in any medium, provided the original work is properly cited.

Toll-like receptors (TLRs) are key players in the pathogenesis of inflammatory conditions including coronary arterial disease (CAD). They are expressed by a variety of immune cells where they recognize pathogen-associated molecular patterns (PAMPs). TLRs recruit adaptor molecules, including myeloid differentiation primary response protein (MYD88) and TIRF-related adaptor protein (TRAM), to mediate activation of MAPKs and NF-kappa B pathways. They are associated with the development of CAD through various mechanisms. TLR4 is expressed in lipid-rich and atherosclerotic plaques. In TLR2 $2^{-/-}$and TLR $4^{-/-}$mice, atherosclerosis-associated inflammation was diminished. Moreover, TLR2 and TLR4 may induce expression of Wnt5a in advanced staged atheromatous plaque leading to activation of the inflammatory processes. TLR9 is activated by CpG motifs in nucleic acids and have been implicated in macrophage activation and the uptake of oxLDL from the circulation. Furthermore, TLR9 also stimulates interferon- $\alpha$ (INF- $\alpha$ ) secretion and increases cytotoxic activity of CD $4^{+}$T-cells towards coronary artery tunica media smooth muscle cells. This review outlines the pathophysiological role of TLR2, TLR4, and TLR9 in atherosclerosis, focusing on evidence from animal models of the disease.

\section{Introduction}

The immune system is an integral component of body defense mechanisms. It is also a fundamental culprit in the pathogenesis of atherosclerosis, a chronic vascular disease that underlies the development of circulatory problems including coronary artery disease and cerebrovascular disease. In these scenarios, atherosclerosis runs a silent asymptomatic course, until stenosis or plaque rupture with superimposed thrombosis manifests clinically as stroke, myocardial infarction (MI), or death. Atherosclerosis involves a chronic and subclinical inflammatory process, initiated by endothelial damage and activation [1]. Subsequently, an elaborate cascade of steps involving various signaling molecules and leukocyte activation and migration follows, leading to the formation of atherosclerotic plaques. This complex process involves extensive interplay between various elements of the innate and adaptive immune systems.

The innate immune system constitutes the first line of defense against pathogens and is highly conserved and universal from an evolutionary perspective [2]. Central to the function of innate immunity is the recognition of pathogenassociated molecular patterns (PAMPs) or disease-associated molecular patterns (DAMPs) by immune-competent cells, such as tissue macrophages and endothelial cells. PAMPs are molecules of microbial origin, and DAMPs are endogenous molecules that normally are sequestered and become released in response to cell injury or endogenous stress signals, such as heat shock proteins (HSPs) [3]. PAMPs and DAMPs are recognized by a number of pattern recognition receptors (PRRs) expressed on sentinel immune cells, which can trigger inflammatory and adaptive immune reactions. Toll-like receptors (TLRs) constitute a major subgroup of pattern recognition receptors [4]. They were first identified in Drosophila mutants that exhibited susceptibility to fungal infections [5]. Subsequently, the human and murine homologs of Toll were identified, and studies showed their essential role in mediating the immune response against bacterial lipopolysaccharide (LPS) [6,7].

Toll-like receptors are part of interleukin-1 receptor/tolllike receptor superfamily. They possess an extracellular 
$\mathrm{N}$-terminal ligand-recognition domain with leucine-rich repeats and a cytoplasmic carboxyl terminal tail with toll/ interleukin-1 receptor (TIR) signaling domains. The extracellular leucine-rich domain binds to PAMPs and forms homoor heterodimers with other TLRs [8]. Vertebrate TLRs are grouped into six subfamilies based on sequence homology, and their structure has been extensively described elsewhere $[9,10]$. At least thirteen mammalian TLRs are known, and these are expressed either on cell surfaces, where they bind microbial membrane components (TLR1, TLR2, TLR4, TLR5, and TLR6) or endosomally (TLR11, TLR12, and TLR13) where they recognize microbial nucleic acids (TLR3, TLR7, TLR8, and TLR9).

TLRs are intimately tied to the process of atheroma formation. TLR4 is expressed in human coronary plaques, and that baseline TLR4 macrophage expression is upregulated by oxidized LDL (oxLDL) [11]. TLR2 and TLR4 are expressed by macrophages, neutrophils, and dendritic cells and have been implicated in the development of coronary artery disease (CAD) through activation of NF- $\kappa$ B pathways [12]. Furthermore, investigators have suggested that the phenomenon of molecular mimicry may be at play at activating innate immune pathways leading to atherosclerosis. TLR4 recognizes chlamydial antigens, and some studies have demonstrated a link between Chlamydia pneumoniae infection and atherothrombosis [13-15]. Although other investigators have failed to replicate this association [16, 17], it nevertheless provides an intriguing insight into the mechanistic link between TLR pathways and atheroma formation. This review article aims to describe the immunological role of TLRs in promoting the development of atherosclerosis, with a primary focus on the function of TLR2, TLR4, and TLR9.

Pathophysiology of Atherosclerosis. Central to the development and progression of atheromas is the interaction between activated monocytes and oxidized LDL (oxLDL) leading to formation of foam cells. Low density lipoprotein (LDL) represents two-thirds of total cholesterol [18]. The American College of Cardiology/American Heart Association define hyperlipidemia associated with increased cardiovascular disease risk as LDL plasma levels above $70-189 \mathrm{mg} / \mathrm{dL}$ (1.81$4.89 \mathrm{mmol} / \mathrm{L}$ ) [19]. Moreover, an LDL/HDL ratio greater than 3 is considered atherogenic [18]. Plasma LDL is transported by apolipoprotein-B lipoprotein complexes in the circulation (ApoB-LPs) such as ApoB-100. In vivo, LDL-C undergoes oxidative modification resulting in the formation of oxLDL, which has strong proinflammatory and immunogenic properties. [20, 21]. Endothelial activation ensues following the lodging of oxLDL in the subendothelial matrix of the tunica intima [22]. Here, oxLDL triggers a response akin to that observed during chronic tissue injury, in that mononuclear leukocytes, primarily monocytes and lymphocytes, are recruited to the "site of injury" where oxLDL lodges $[23,24]$. Tissue macrophages scavenge oxLDL and become transformed into foam cells. These lipid-laden foam cells form the basis of the initial lesion. The accumulation of foam cells gives rise to fatty streaks [25]. Furthermore, as the plaque evolves, intermediate lesions are formed, characterised by smooth muscle cell (SMC) proliferation and migration from the tunica media to the tunica intima. SMCs also become lipid-laden. Late stages of plaque evolution include atheromatous plaques and fibroatheromas [26]. In atheromas, foam cells undergo apoptosis and accumulate, forming a lipid-rich necrotic core [27]. Angiogenesis is evident in plaque development and its role is poorly understood. Some authors postulate that angiogenesis is triggered by cytokines secreted from activated macrophages to provide monocytes that can differentiate into tissue macrophages, to phagocytose the apoptotic foam cells [28]. Other authors propose that angiogenesis in these lesions serves to perfuse the hypoxic environment created by the cellular debris [29]. The consensus is that angiogenesis may set up a vicious cycle whereby there is a continual supply of monocytes which differentiate into tissue macrophages and become transformed into foam cells as a result of oxLDL uptake. On the other hand, fibroatheromas consist of extracellular matrix secreted by SMCs, and there is also evidence of calcified deposits. This is the basis of the fibrous cap formation [27]. In end-stage CAD, fibroatheromas may further evolve into complicated unstable lesions with surface defects and multiple necrotic cores. Complications from such lesions include erosion, rupture, fissure, and ulceration, resulting in various clinical manifestations, such as acute coronary syndromes $[26,30]$.

Epidemiology of CAD. CAD remains a prevalent cause of global mortality, accounting for an approximate 1.8 million annual deaths in Europe alone, which translates to $20 \%$ of total European mortality [31]. Low- and middle-income countries in Eastern Europe and Central Asia are now the most heavily affected by CAD. This is primarily due to the fact that these regions constitute the majority of the world's population. Contributing to the shift in CAD epidemiology is the increasing affluence in developing regions, including Latin America, Sub-Saharan Africa, Middle East, and South East Asia. The increasing urbanization, industrialization, and adoption of Western-style lifestyles that follows from economic growth impact negatively on cardiovascular mortality and have extensive socioeconomic implications [32]. Furthermore, the shift in population demographics resulting in increased life expectancy further compounds the clinical and public health burden exerted by CAD, particularly in Western countries [33].

\section{TLR Signaling}

TLRs are type 1 transmembrane glycoproteins comprised of extracellular, transmembrane, and intracellular signaling domains that are expressed either on the plasma membrane or on intracellular endolysosomal compartments. The cytoplasmic signaling domain is shared with that of the interleukin-1 (IL-1) receptor (the toll/IL-1R domain, TIR), and as a consequence of this homology TLRs activate pathways shared with IL-1R [12]. Upon ligand binding, the TLR signaling cascade is initiated by the TIR domain via a number of cytoplasmic adapter molecules. These include myeloid differentiation primary response protein (MyD88), 
TIR-domain-containing adaptor protein (TIRAP), and TRIFrelated adaptor molecule (TRAM) [34].

The MyD88 pathway is essential for all TLR signaling, with exception of TLR3. MyD88 activates IL-1R associated kinases (IRAKs), IRAK-1 and IRAK-4, and TNF-receptor associated factor-6 (TRAF-6) [35, 36]. Consequently, recruitment of a number of proteins activates a complex containing TGF- $\beta$-activated kinase 1 (TAK1), TAK1-binding protein- 1 (TAB1), TAB2, and TAB3 [37]. The TAK1/TAB complex turn leads to activation of both the MAPK and NF- $\kappa$ B signaling pathways [38]. These steps result in activation of a number of genes coding for proinflammatory cytokines and chemokines, including TNF- $\alpha$, IL-1, and Il-6 [39].

TLR3 and TLR4 can also engage an MyD88-independent signaling pathway [40]. This requires TRIF and TRAM adapter proteins that lead to phosphorylation of interferon regulatory factor 3 (IRF3) and NF- $\kappa \mathrm{B}$ transcription factors [41]. The major outcome of TRIF-dependent TLR4 signaling is the production of type I interferons that have antiviral and antiproliferative activity $[42,43]$.

The balance between MyD88-dependent and TRIFdependent TLR signaling is essential for proper immune function. These two pathways show reciprocal interaction and regulation. Wang et al. demonstrated that Nrdp1 (E3 ubiquitin ligase) inhibits the production of proinflammatory cytokines but increases IFN- $\beta$ production in TLR-activated macrophages. This is achieved by suppressing the MyD88dependent activation of NF- $\kappa \mathrm{B}$ through ubiquitination of MyD88 [44]. Conversely, Liu et al. showed that intracellular MHC class II molecules in antigen presenting cells can activate both MyD88 and TRIF cascades, leading to production of proinflammatory cytokines and interferons [45].

In addition to the activation of NF- $\kappa \mathrm{B}$ transcription factor in MyD88-dependent and MyD88-independent fashion, TLR2 has been implicated in the stimulation of proapoptotic pathways. Aliprantis et al. first demonstrated that bacterial lipoproteins induce monocyte apoptosis in vitro [46]. Subsequently they demonstrated that MyD88 is the common mediator of TLR2-induced apoptosis and NF- $\kappa \mathrm{B}$ activation and that TLR2 induces apoptosis through the FADD-caspase pathway in a manner analogous to members of the TNFR family $[47,48]$. The in vivo relevance of TLR2 proapoptotic activity in either reinforcing or terminating the inflammatory response remains elusive, and its specific role in chronic inflammatory processes is poorly understood.

2.1. TLR Ligands. TLRs are able to bind a wide range of both endogenous and exogenous ligands. Primarily, they function as receptors for molecular domains borne on bacterial or viral pathogens. TLRs expressed on the plasma membrane recognize cell-wall components of bacteria and fungi, while those expressed on internal endolysosomal compartments bind viral PAMPs. Specifically, TLR2 binds bacterial lipoproteins, and TLR4 is primarily activated by bacterial lipopolysaccharide and TLR9 by unmethylated CpG nucleotide sequences [12]. In addition to exogenous ligands of microbial origin, TLRs are able to bind a wide range of endogenous ligands. These endogenous ligands are host-derived molecules that stimulate TLR signaling in the absence of infection, and they have been extensively reviewed elsewhere $[49,50]$. Endogenous ligands include various extracellular matrix components, including fibronectin [51], fibrinogen [52], hyaluronic acid derivatives [53], heat shock proteins [54], and minimally oxidized low density lipoprotein [55]. These ligands are either actively released by cells at sites of injuy or passively released by cells damaged from inflamed tissues.

The evolving atherosclerotic plaque is a site of matrix turnover, tissue remodeling, and cell necrosis and hence contains a number of endogenous TLR ligands. Of particular interest are heat shock proteins (HSPs), which have been identified as powerful activators of innate immune function. Various investigators report that HSP60 induces a proinflammatory response in a TLR2 and TLR4 dependent fashion [56-58]. However, this hypothesis has been extensively challenged. Investigations showed that contamination by LPS in the HSP preparations is responsible for the observed TLR4 activation $[59,60]$. LPS is a powerful inducer of TLR activation even in minute quantities, and LPS contamination results from the production of recombinant HSP in Escherichia coli.

TLR signaling cascades can be activated by a broad range of host-derived molecules in the absence of exogenous infection, and this plays a central role in the development and progression of atherosclerosis. The subsequent sections of this review focus on the roles of TLR2, TLR4, and TLR9 in the pathogenesis of atherosclerosis. Figure 1 outlines the key mechanisms from functional and animal studies implicating TLR2 and TLR4 in atherosclerosis.

2.2. TLR2 and Atherosclerosis. TLR2 is a cell surface receptor that binds a wide range of microbial components, such as gram-positive-derived lipoteichoic acid, bacterial lipoproteins, and zymosan [61]. It is expressed in a number of immune cells, the endothelium, and epithelial cells [62]. TLR2 has a unique ability to form functional heterodimers with either TLR1 or TLR6 resulting in relatively broad ligand specificity [63]. TLR2 expression, along with that of TLR1 and TLR4, is markedly increased in endothelial cells overlying atheromas [64]. Furthermore, endothelial TLR2 expression and activation may occur at areas of turbulent blood flow, such as the areas of lesion predilection within the aortic tree and heart. In vitro experiments using human coronary artery endothelial cells exposed to laminar blood flow showed lower levels of TLR2 expression when compared to endothelial cells exposed to static or turbulent flow [65]. Laminar flow at or above $0.5 \mathrm{~N} / \mathrm{m}^{2}$ inhibits endothelial TLR2 expression via protein kinase CK2, which phosphorylates a transcription factor known as specificity protein-1 (SP1). This prevents SP1 binding to the TLR2 promoter, thereby reducing TLR2 expression. In doing so, flow suppression of TLR2 expression is considered to be atheroprotective [65]. Mullick et al. showed that, in atherosclerosis-susceptible LDLR-deficient $\left(\mathrm{LDLR}^{-/-}\right.$) mice, complete deficiency of TLR2 leads to a reduction in atherosclerosis, whereas expression of TLR2 only on bone marrow derived cells has no impact on atherosclerosis [66]. This experiment showed that TLR2 expression on non-bone marrow derived cells, such as vascular endothelium, at sites of nonlaminar flow contributes to the atherosclerosis. Furthermore, the authors showed that on 


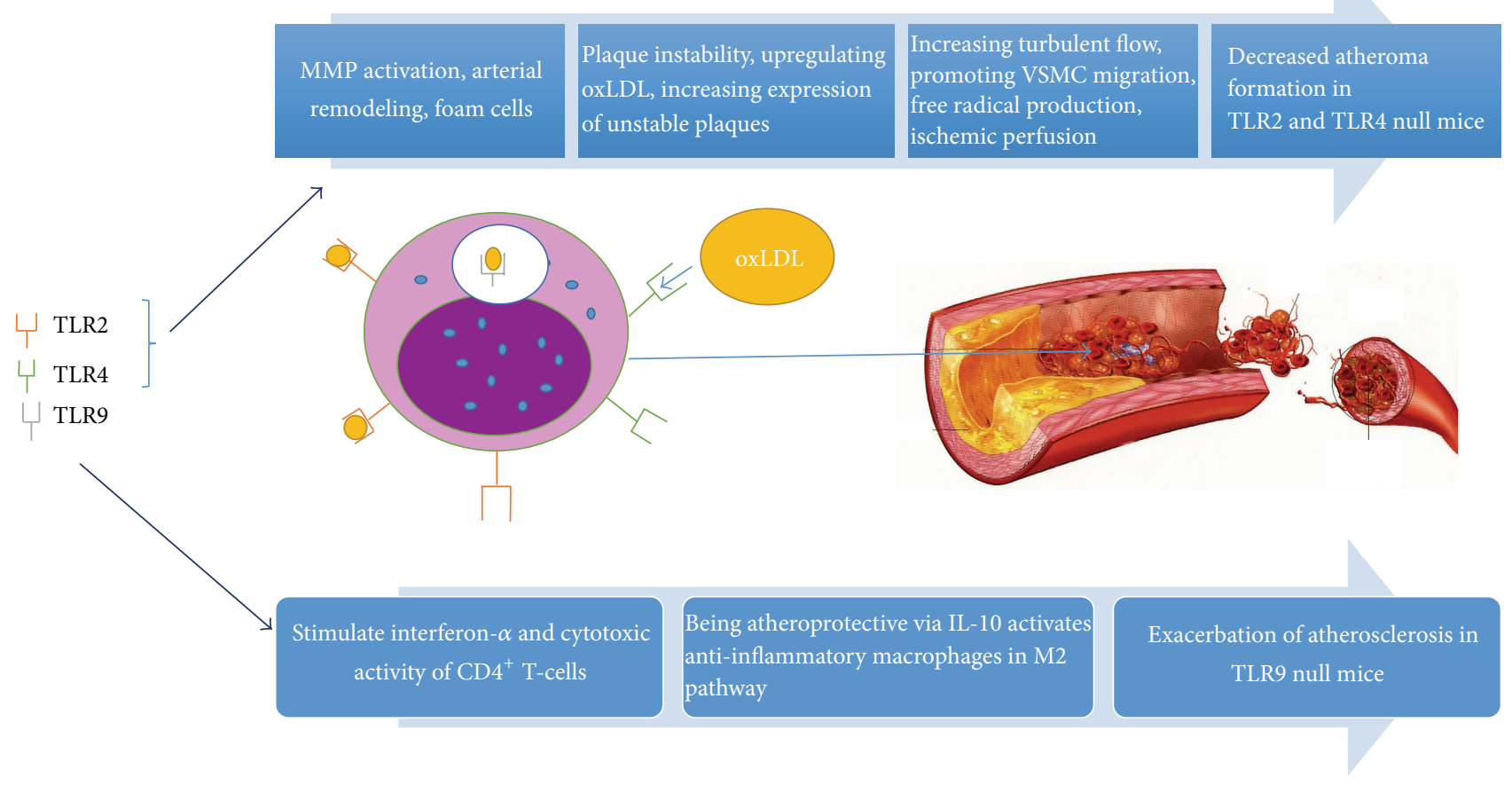

FIGURE 1: An overview of the proatherogenic effects of TLR2 and TLR4 compared to antiatherogenic effects of TLR9.

administration of Pam3CSK4 (a synthetic TLR2/TLR1 agonist), atherosclerotic burden was dramatically increased in $\mathrm{LDLR}^{-/-}$mice. The proatherogenic effect of Pam3CSK4 was not observed in LDLR $^{-/-}$mice with complete TLR2 deficiency or in $\mathrm{LDLR}^{-/-}$mice with a deficiency of TLR2 only in bone marrow derived cells. This finding reinforces the role of TLR2 in promoting atherosclerosis through its action in cells of non-bone marrow origin.

Further investigations by Mullick et al. using $\mathrm{LDLR}^{-/-}$ mice showed that aortic endothelial cell TLR2 expression was confined to areas of nonlaminar flow, specifically in the lesser curvature of the aorta, and that hyperlipidemia increases endothelial TLR2 expression [67]. Furthermore, the authors generated chimeric mice with green fluorescent protein (GFP) expression in $\mathrm{BM}$ derived cells $\left(\mathrm{BMGFP}^{+}\right)$. Bone marrow reconstitution of $L D L R^{-/-}$and $L D L R^{-/-} T L R 2^{-/-}$mice with $\mathrm{BMGFP}^{+}$cells showed that hyperlipidemia increases lesser curvature $\mathrm{BMGFP}^{+}$leukocyte accumulation, lipid accumulation, and foam cell generation, whereas hyperlipidemic double mutant $\mathrm{BMGFP}^{+} L D L R^{-/-} T L R 2^{-/-}$mice had reduced lesser curvature atherogenic activity. This study showed that endothelial TLR2 expression is linked to early atherosclerosis in murine models.

The role of TLR2 in atherosclerosis has been reinforced by other studies. Using $\mathrm{ApoE}^{-/-}$atherosclerotic mice Schoneveld et al. showed that exogenous TLR2 activation increases atherosclerotic plaque formation and plaque-media ratio. TLR2 is involved not only in the initial intimal lesion formation but also in development of occlusive disease [68]. Furthermore, TLR2 promotes vascular smooth muscle cell (VSMC) migration from tunica media to the intima in an
IL-6 dependent manner [69]. Genetic deficiency of TLR2 reduces diet-induced atherosclerosis in $\mathrm{ApoE}^{+/-}$mice [70], and TLR2 expression and activation regulates the inflammatory processes and ROS production following vascular injury in mouse models [71]. Aside from the involvement of TLR2 in atheroma development, evidence shows that TLR2 contributes to coronary endothelial dysfunction after ischemia/reperfusion by activating neutrophils and free radical production [72].

Scavenger receptors such as the CD36 coreceptor have been linked to activation of TLR2 [52]. CD36 functions in the recognition of various endogenous ligands, including oxLDL and the uptake of fatty acids. Nonetheless, even though TLR2 participates in the immune response to oxLDL, it is not a primary culprit in formation of foam cells unlike TLR4 and CD36 [73].

Other ligands implicated in TLR2 activation include high-mobility group box 1 protein (HMGB1). This is a nuclear transcription factor secreted by macrophages, monocytes, and dendritic cells that is expressed in atherosclerotic lesions [74]. It binds to TLR2 and triggers release of proinflammatory cytokines [75]. HMGB1 also has proatherogenic effects and stimulates macrophage migration in atherosclerotic lesions [55].

Members of Wnt family of glycoproteins such as Wnt5a have been reported to be coexpressed with TLR2 and TLR4 in macrophage rich regions of more advanced staged atheromatous plaques [76]. oxLDL can induce mRNA expression of Wnt5a, which correlates with the severity of atherosclerotic lesions in human studies [77]. Wnt5a has been implicated in the regulation of cholesterol transport in mouse macrophages 
[78]. Recently, Wnt5a pathways have shown playing a critical role in foam cell formation and oxLDL uptake [79]. The complex role of Wnt5a pathways in atherosclerosis has been extensively reviewed by Bhatt and Malgor [80]. Taken together, these studies highlight the elaborate signaling pathways involving TLR2 and its important role in driving atherogenesis.

2.3. TLR4 and Atherosclerosis. TLR4 resides in the plasma membrane, where it recognizes a number of exogenous ligands and activates a series of inflammatory cascades in an NK- $\kappa$ B-dependent fashion [81]. Several lines of clinical and experimental evidence support its role in the pathogenesis of atheromas. Human studies showed that $\mathrm{CD} 14^{+}$monocyte TLR4 expression is increased in unstable angina and acute MI compared to control and stable angina groups [82, 83]. Satoh et al. showed that activation of TLR4 is associated with heart failure following MI [84]. Conversely, Tapp et al. showed that $\mathrm{MI}$ is associated with increased numbers of TLR $4^{+}$monocyte subsets, but not with higher TLR4 expression by individual monocytes [85].

Atherosclerotic plaque cells, in a manner analogous to TLR2, express TLR4 [64]. TLR4 levels are upregulated by oxLDL and Howell et al. showed that in murine models TLR4 is necessary for the oxLDL-induced macrophage differentiation into foam cells [86]. Similarly, TLR4 is a critical mediator in oxLDL-induced inflammatory cytokine expression in vascular smooth muscle cells [87]. Minimally modified LDL (a subtype of oxLDL that is essential for atherosclerosis) induces ROS production and macrophage cytoskeletal rearrangements in a TLR4 dependent and MyD88-independent manner [55, 88]. The spleen tyrosine kinase SYK binds to the cytoplasmic domain of TLR4 and mediates macrophage activation, membrane ruffling, macropinocytosis, lipid accumulation, and their consequent transformation into lipidladen foam cells $[89,90]$.

Further experimental evidence from loss-of-function animal models supports the role of TLR4 in atherosclerosis. Atherosclerosis-prone ApoE ${ }^{-/-}$mice with deficiency of TLR4 or MyD88 show attenuation in atherosclerosis development through decreased macrophage recruitment [91, 92]. Higashimori et al. showed that TLR4 contributes to earlystage intimal foam cell accumulation at lesion-prone aortic sites in $\mathrm{ApoE}^{-/-} \mathrm{TLR}^{-/-}$mice, with a 75\% reduction in intimal lipid levels compared to $\mathrm{ApoE}^{-/-}$controls [93]. This study also showed that TLR4 is a more powerful contributor to foam cell formation than TLR2. Coenen et al. demonstrated that mice lacking macrophage TLR4 expression have reduced atherosclerotic lesion size when fed low-fat diets, despite no observed difference in body composition and plasma lipids [94]. TLR4 is also involved in outward arterial remodeling. This process compensates for loss of the vascular lumen due to plaque accumulation and involves collagen matrix degradation by matrix metalloprotease- 9 (MMP-9), which is activated by TLR4 [95]. Disordered arterial remodeling contributes to atherosclerosis and vascular restenosis. TLR4 $4^{-/-}$ mice show no outward arterial remodeling in carotid artery ligation and femoral artery cutoff models [96].
In addition to the established function of TLR4 in atheroma development, it also plays a critical role in the progression and eventual rupture of atherosclerotic plaques leading to the formation of occlusive thrombus. Ishikawa et al. demonstrated an increased expression of TLR4, but not TLR2, in ruptured human coronary atherosclerotic plaques, with TLR4 immunostaining observed in the infiltrating macrophages [97]. Recent literature further implicates TLR4 in plaque instability. Gargiulo et al. showed that specific components of oxLDL that accumulate in atheromas enhance the release of proinflammatory cytokines and upregulate MMP-9 in a TLR4/NF- $\kappa$ B-dependent fashion [98]. This investigation directly implicates the role of lipid derivatives as endogenous TLR4 ligands that contribute to matrix breakdown.

The extracellular matrix (ECM) is a key player in the progression of atherosclerotic disease, and several studies have described the structural alterations that develop during atherosclerosis $[83,99]$. Chronically inflamed tissues express extracellular matrix (ECM) proteins that regulate the migration of leukocytes and other immune cells to sites of injury. While healthy human endothelium rests on an ECM composed of collagen IV and laminin, the ECM of atherosclerotic vessels contains abundant fibronectin in both human and mouse models $[100,101]$. Fibronectin occurs in two forms generated by alternative splicing, plasma fibronectin $(\mathrm{pFN})$ and cellular fibronectin (cFN). pFN is a soluble dimer secreted by hepatocytes. cFN is expressed in the ECM of various tissues and is a multimer that forms fibrils and contains extra domains A and B (EDA and EDB) [102]. cFN is synthesised by vascular smooth muscle and endothelial cells. The extra domain $\mathrm{A}$ in fibronectin $\left(\mathrm{EDA}^{+} \mathrm{FN}\right)$ is implicated in a number of biological processes, including atherosclerosis. Deletion of the alternatively spliced EDA exon reduces the number and size of atherosclerotic lesions in ApoE null mice $[103,104]$. In vitro studies also suggested that the FN EDA domain activates TLR4 [51]. Further investigations using ApoE null mice with either constitutive expression or knockout of the fibronectin EDA domain showed that $\mathrm{EDA}^{+} \mathrm{FN}$ promotes progression of atherosclerosis through a mechanism that is partially dependent on TLR4 [105]. The authors showed that $\mathrm{EDA}^{+} \mathrm{FN}$ drives macrophage recruitment into developing plaques through TLR4 signaling. Comparably, Prakash et al. showed that platelet TLR4 facilitates the prothrombotic effects of cellular $\mathrm{EDA}^{+} \mathrm{FN}$ on platelet aggregation and arterial thrombosis [106]. $\mathrm{EDA}^{+} \mathrm{FN}$ mice lacking platelet TLR4 showed decreased thrombus formation and a slower thrombus growth rate compared with control mice expressing platelet TLR4, further highlighting the proatherogenic effect of the FN-TLR4 interaction.

2.4. TLR9 and Atherosclerosis. While TLR 2 and TLR4 are expressed on the cell surface, TLR9 colocalises to the endoplasmic reticulum in various cell types, including B-cells, macrophages, dendritic cells, and plasma cells [107]. In the ER, TLR9 is able to detect and bind unmethylated oligodeoxynucleotide CpG motifs in microbial DNA sequences and trigger inflammatory responses [108]. Unmethylated CpG sequences are rare in eukaryotic genomes but abundant in prokaryotes. 
Apart from its role in the recognition of bacterial DNA, TLR9 has been closely linked with the development of atherosclerotic lesions, since it is activated by CpG motifs in nucleic acids that are released during vascular necrosis. Activation of TLR9 stimulates the transformation of murine macrophages into foam cells in an NF- $\kappa$ B- and IRF7-dependent manner [109]. This process is inhibited by the activation of liver $\mathrm{x}$-receptors, which are transcriptional regulators of lipid and carbohydrate metabolism [110].

In addition, activation of TLR9 via CpG-containing nucleotide sequences in plasmacytoid dendritic cells stimulates interferon- $\alpha$ (INF- $\alpha$ ) secretion and increases the cytotoxic activity of $\mathrm{CD} 4^{+} \mathrm{T}$-cells towards vascular smooth muscle cells [111].

However, some investigators have suggested that TLR9 is protective against atherosclerosis. In vitro activation of TLR9 stimulates interleukin-10 (IL-10) production, which in turn inhibits the expression of INF- $\alpha$ secreted by plasma dendritic cells and inhibits $\mathrm{CD} 4^{+} \mathrm{CD} 25^{+} \mathrm{T}$-cell proliferation $[112,113]$. Loss-of-function animal models have been used to further elucidate the role of TLR9 in atheroma. Koulis et al. used a double knockout mouse model lacking both TLR9 and ApoE to compare aortic sinus atherosclerotic lesion development. The investigators showed a 33\% increase in lipid deposition and atherosclerotic plaque size in $\mathrm{ApoE}^{-/-} / \mathrm{TLR}^{-/-}$mice compared to $\mathrm{ApoE}^{-1-}$ mice [114]. Furthermore, there was significant accumulation of macrophages, dendritic cells, and INF- $\alpha$ in vasculature of $\mathrm{ApoE}^{-/-} / \mathrm{TLR}^{-/-}$mice compared to control animals. Loss of TLR9 function thus exacerbates atherosclerosis in ApoE null mice exposed to a high fat diet.

Other investigators have reported contradictory findings. Pharmacologic inactivation of TLR9 pathways in animal models results in a reduction in atherosclerotic lesion generation in $\mathrm{ApoE}^{-/-}$mice and reduced instability of vulnerable plaques [115]. Ma et al. showed that inactivation of TLR9 using immunoregulatory oligodeoxynucleotides such as IRS869 reduces plaque burden and shunts the activities of proinflammatory macrophages (M1) into anti-inflammatory macrophages (M2). Krogmann et al. investigated the effect of administering intravenous ODN1826 (type B oligodeoxynucleotide that activates TLR9). They showed that stimulation of TLR9 impairs reendothelialization following acute vascular injury and increases plaque development in $\mathrm{ApoE}^{-/-}$mice [116]. Nonetheless, pharmacologic TLR9 activation did not alter the endothelium-dependent vasodilation, suggesting that TLR9 activation only affects the regenerative process but not the vasoactive function of endothelial cells. Both pro- and antiatherosclerotic effects of TLR9 have been described. One possible explanation for the discrepancies between the investigations reported by Krogmann et al. includes differences in the oligodeoxynucleotide dosage regime, as development of atherosclerosis requires chronic sustained inflammatory trigger [116]. Further investigations are needed to further define the role of TLR9 agonists in atherosclerotic disease.

2.5. Regulatory T-Cells and TLR Signaling in Atherosclerosis. Atherosclerosis is a highly complex process that involves multiple signaling cascades and a wide variety of cell types, including monocytes, macrophages, VSMCs, and various subtypes of $\mathrm{T}$ lymphocytes. T-cell subtypes exert differing effects on atherogenesis. Th1 cells are proatherogenic while Th2 and Tregs (T-regulatory cells) have atheroprotective effects $[117,118]$. The function of different T-cell subtypes in atherosclerosis has been recently reviewed elsewhere [119, 120]. Of particular interest is the link between Tregs and atherosclerosis. Subramanian et al. investigated the role of monocyte-derived $\mathrm{CD}_{11 c^{+}}$dendritic cells. In this study, $\mathrm{LDLR}^{-/-}$mice were reconstituted with bone marrow cells where $\mathrm{CD}_{11 c^{+}}$cells lacked the TLR adaptor MyD88 [121]. This decreases their ability to activate T-effector cells and was expected to produce a decrease in atherosclerosis [122]. On the contrary, the study demonstrated an increase in aortic root atheroma size and monocyte infiltration, with no differences in lipoprotein levels. This effect was due to the loss of Treg-mediated suppression of MCP-1, and the data demonstrated the atheroprotective role of Treg cells in murine models. It also provides interesting insight into the function of TLRs at the crossroads of innate and adaptive immunity in atherosclerosis, which might be useful in the development of novel therapeutic strategies [123].

2.6. TLR Polymorphism in Atherosclerosis. Further evidence supporting the role of TLRs in atheroma development comes from genetic association studies. Most studies have focused on two missense polymorphism types in TLR4, Asp299Gly and Thr399Ile, and conflicting associations have been reported. Some investigators reported a reduced risk of atherosclerosis in carriers of the Asp299Gly TLR4 polymorphism [124], which was not reproduced in other investigations [125]. Other case-control candidate genes have identified an association between the TLR4 polymorphism and acute myocardial infarction, with a reduced incidence of cardiovascular events in the 299GLy allele [126, 127]. However, a meta-analysis by Koch et al. showed no association between TLR4 variants and myocardial infarction in a Caucasian cohort [128]. Population-specific differences in risk allele frequency possibly account for the different associations reported in the literature $[129,130]$.

\section{Conclusion}

TLRs form part of the innate arm of the immune system where they play an integral role in defense mechanisms against pathogens. They are expressed on a number of immune cells including macrophages, monocytes, and dendritic cells. TLRs distinguish between host molecules and PAMPs upon binding to the ligand and thereby trigger inflammatory response via NK- $\kappa \mathrm{B}$ pathways. MyD88 plays a critical role in TLR signaling. MyD88 deficiency in myeloid cells has been shown to inhibit macrophage recruitment and activation of the M1 system. In vivo and ex vivo studies have linked MyD88-dependent growth factors produced by endothelial cells to initiating inflammation and development of atherosclerosis by priming the monocytes in arterial and adipose tissues to differentiate into M1-proinflammatory macrophages instead of M2 anti-inflammatory macrophages. 
Different subtypes of TLRs are involved in different aspects of inflammatory response. TLR 2 and TL4 are strongly implicated in atheroma development and progression, leading to coronary artery disease. This is evidenced by a number of in vitro and animal studies using atherosclerosis-prone LDLR or ApoE deficient mice. Moreover, the development of atherosclerotic plaques often requires more than just TLRs, and coreceptors such as CD36 have been linked to TLR2 activation and inducing atherosclerotic change. Even though TLR2 and TLR4 are often labelled as "atherogenic promoters," they are not considered as the primary culprit behind certain inflammatory changes such as formation of foam cells and generation of oxLDL. Furthermore, the presence of TLR4 in unstable plaques suggests that it is a major driver of CAD progression. TLR4 upregulates matrix metallopeptidases such as MMP-9 which makes plaques prone to rupture. The precise function of TLR9 in atherosclerosis is yet to be defined, with conflicting studies reporting both proatherogenic and antiatherogenic effects. Clearly, TLRs are promising therapeutic targets and possible biomarker candidates for a wide range of pathologies, but further studies are required in order to fully define their function.

\section{Abbreviations}

\begin{tabular}{|c|c|}
\hline CAD: & Coronary arterial disease \\
\hline $\mathrm{NK}-\kappa \mathrm{B}:$ & $\begin{array}{l}\text { Nuclear factor kappa-light-chain } \\
\text { enhancer B-cells }\end{array}$ \\
\hline TLRs: & Toll-like receptors \\
\hline CD4 ${ }^{+}$T-cells: & Cluster of differentiation 4 T-cells \\
\hline $\operatorname{ApoE}^{-/-}:$ & Absence of apolipoprotein E \\
\hline Wtn5a: & $\begin{array}{l}\text { Wingless-type MMTV integration site } \\
\text { family member } 5 \mathrm{a}\end{array}$ \\
\hline MyD88: & $\begin{array}{l}\text { Myeloid differentiation primary } \\
\text { response gene }\end{array}$ \\
\hline PRRs: & Pattern recognition receptors \\
\hline OxLDL: & Oxidized low density lipoprotein \\
\hline MM-LDL: & $\begin{array}{l}\text { Minimally modified low density } \\
\text { lipoprotein }\end{array}$ \\
\hline PAMPs: & Pathogen-associated molecular patterns \\
\hline DAMPs: & Disease-associated molecular patterns \\
\hline VSMCs: & Vascular smooth muscle cells \\
\hline CVD: & Cardiovascular disease \\
\hline TIRAP: & TIR-domain-containing adaptor protein \\
\hline TRAM: & TIRF-related adaptor molecule \\
\hline SP1: & Specificity protein-1 \\
\hline NBM: & Non-bone marrow origin \\
\hline TNF: & Tumour necrosis factor \\
\hline IL-1/IL-6/IL-18: & $\begin{array}{l}\text { Interleukin-1/interleukin-6/interleukin- } \\
18\end{array}$ \\
\hline MMP-9: & Metalloproteinase- 9 \\
\hline ECs: & Endothelial cells \\
\hline ECM: & Extracellular matrix \\
\hline FN: & Fibronectin \\
\hline EDA: & Extra domain A of fibronectin \\
\hline ODN: & Oligodeoxynucleotide \\
\hline TNF- $\alpha$ : & Tumour necrosis factor-alpha \\
\hline BM: & Bone marrow \\
\hline LPS: & Lipopolysaccharides \\
\hline
\end{tabular}

HDL: High density lipoprotein

Pam3/CSK4 ETC: N-Plamitoyl-(S)-[2,3bis(palmitoyloxy)-(2RS)-propyl]/CsySer-Lys4 (Pam3/CSK4).

\section{Competing Interests}

The authors confirm that this article content has no conflict of interests.

\section{References}

[1] P. Libby, P. M. Ridker, and A. Maseri, "Inflammation and atherosclerosis," Circulation, vol. 105, no. 9, pp. 1135-1143, 2002.

[2] C. A. Janeway Jr. and R. Medzhitov, "Innate immune recognition," Annual Review of Immunology, vol. 20, no. 1, pp. 197-216, 2002.

[3] J. L. Witztum and A. H. Lichtman, "The influence of innate and adaptive immune responses on atherosclerosis," Annual Review of Pathology: Mechanisms of Disease, vol. 9, pp. 73-102, 2014.

[4] O. Takeuchi and S. Akira, "Pattern recognition receptors and inflammation," Cell, vol. 140, no. 6, pp. 805-820, 2010.

[5] B. Lemaitre, E. Nicolas, L. Michaut, J.-M. Reichhart, and J. A. Hoffmann, "The dorsoventral regulatory gene cassette spatzle/Toll/Cactus controls the potent antifungal response in Drosophila adults," Cell, vol. 86, no. 6, pp. 973-983, 1996.

[6] R. Medzhitov, P. Preston-Hurlburt, and C. A. Janeway Jr., "A human homologue of the Drosophila Toll protein signals activation of adaptive immunity," Nature, vol. 388, no. 6640, pp. 394-397, 1997.

[7] K. Hoshino, O. Takeuchi, T. Kawai et al., "Cutting edge: tolllike receptor 4 (TLR4)-deficient mice are hyporesponsive to lipopolysaccharide evidence for TLR4 as the Lps gene product," Journal of Immunology, vol. 162, no. 7, pp. 3749-3752, 1999.

[8] T. Kawai and S. Akira, "The roles of TLRs, RLRs and NLRs in pathogen recognition," International Immunology, vol. 21, no. 4, pp. 317-337, 2009.

[9] I. Botos, D. M. Segal, and D. R. Davies, "The structural biology of Toll-like receptors," Structure, vol. 19, no. 4, pp. 447-459, 2011.

[10] N. Matsushima, T. Tanaka, P. Enkhbayar et al., "Comparative sequence analysis of leucine-rich repeats (LRRs) within vertebrate toll-like receptors," BMC Genomics, vol. 8, article 124, 2007.

[11] X. H. Xu, P. K. Shah, E. Faure et al., "Toll-like receptor4 is expressed by macrophages in murine and human lipidrich atherosclerotic plaques and upregulated by oxidized LDL," Circulation, vol. 104, no. 25, pp. 3103-3108, 2001.

[12] J. E. Cole, E. Georgiou, and C. Monaco, "The expression and functions of toll-like receptors in atherosclerosis," Mediators of Inflammation, vol. 2010, Article ID 393946, 18 pages, 2010.

[13] R. Ezzahiri, F. R. M. Stassen, H. R. M. Kurvers, V. Dolmans, P. J. E. H. M. Kitslaar, and C. A. Bruggeman, "Chlamydia pneumoniae infections augment atherosclerotic lesion formation: a role for serum amyloid P," Acta Pathologica, Microbiologica, et Immunologica Scandinavica, vol. 114, no. 2, pp. 117-126, 2006.

[14] L. Törmäkangas, L. Erkkilä, T. Korhonen et al., "Effects of repeated Chlamydia pneumoniae inoculations on aortic lipid accumulation and inflammatory response in C57BL/6J mice," Infection and Immunity, vol. 73, no. 10, pp. 6458-6466, 2005.

[15] E. Blessing, L. A. Campbell, M. E. Rosenfeld, N. Chough, and C.-C. Kuo, "Chlamydia pneumoniae infection accelerates 
hyperlipidemia induced atherosclerotic lesion development in C57BL/6J mice," Atherosclerosis, vol. 158, no. 1, pp. 13-17, 2001.

[16] K. Aalto-Setälä, K. Laitinen, L. Erkkilä et al., "Chlamydia pneumoniae does not increase atherosclerosis in the aortic root of apolipoprotein E-deficient mice," Arteriosclerosis, Thrombosis, and Vascular Biology, vol. 21, no. 4, pp. 578-584, 2001.

[17] G. Caligiuri, M. Rottenberg, A. Nicoletti, H. Wigzell, and G. K. Hansson, "Chlamydia pneumoniae infection does not induce or modify atherosclerosis in mice," Circulation, vol. 103, no. 23, pp. 2834-2838, 2001.

[18] J. Millán, X. Pintó, A. Muñoz et al., "Lipoprotein ratios: physiological significance and clinical usefulness in cardiovascular prevention," Vascular Health and Risk Management, vol. 5, pp. 757-765, 2009.

[19] N. J. Stone, J. G. Robinson, A. H. Lichtenstein et al., "2013 ACC/AHA guideline on the treatment of blood cholesterol to reduce atherosclerotic cardiovascular risk in adults: a report of the American College of Cardiology/American Heart Association Task Force on Practice Guidelines," Journal of the American College of Cardiology, vol. 63, no. 25, pp. 2889-2934, 2014.

[20] S. Garrido-Urbani, M. Meguenani, F. Montecucco, and B. A. Imhof, "Immunological aspects of atherosclerosis," Seminars in Immunopathology, vol. 36, no. 1, pp. 73-91, 2014.

[21] I. Levitan, S. Volkov, and P. V. Subbaiah, "Oxidized LDL: diversity, patterns of recognition, and pathophysiology," Antioxidants and Redox Signaling, vol. 13, no. 1, pp. 39-75, 2010.

[22] M. F. Khalil, W. D. Wagner, and I. J. Goldberg, "Molecular interactions leading to lipoprotein retention and the initiation of atherosclerosis," Arteriosclerosis, Thrombosis, and Vascular Biology, vol. 24, no. 12, pp. 2211-2218, 2004.

[23] P. Libby, "Changing concepts of atherogenesis," Journal of Internal Medicine, vol. 247, no. 3, pp. 349-358, 2000.

[24] G. K. Hansson, "Immune mechanisms in atherosclerosis," Arteriosclerosis, Thrombosis, and Vascular Biology, vol. 21, no. 12, pp. 1876-1890, 2001.

[25] H. C. Stary, A. B. Chandler, S. Glagov et al., "A definition of initial, fatty streak, and intermediate lesions of atherosclerosis. A report from the Committee on Vascular Lesions of the Council on Arteriosclerosis, American Heart Association," Circulation, vol. 89, no. 5, pp. 2462-2478, 1994.

[26] H. C. Stary, A. B. Chandler, R. E. Dinsmore et al., "A definition of advanced types of atherosclerotic lesions and a histological classification of atherosclerosis. A report from the committee on vascular lesions of the council on arteriosclerosis, American Heart Association," Circulation, vol. 92, no. 5, pp. 1355-1374, 1995.

[27] A. J. Lusis, “Atherosclerosis," Nature, vol. 407, no. 6801, pp. $233-$ $241,2000$.

[28] W.-S. Lee, M. K. Jain, B. M. Arkonac et al., "Thy-1, a novel marker for angiogenesis upregulated by inflammatory cytokines," Circulation Research, vol. 82, no. 8, pp. 845-851, 1998.

[29] P. R. Moreno, K. R. Purushothaman, E. Zias, J. Sanz, and V. Fuster, "Neovascularization in human atherosclerosis," Current Molecular Medicine, vol. 6, no. 5, pp. 457-477, 2006.

[30] V. Fuster, P. R. Moreno, Z. A. Fayad, R. Corti, and J. J. Badimon, "Atherothrombosis and high-risk plaque: part I: evolving concepts," Journal of the American College of Cardiology, vol. 46, no. 6, pp. 937-954, 2005.

[31] M. Nichols, N. Townsend, P. Scarborough, and M. Rayner, "Cardiovascular disease in Europe 2014: epidemiological update," European Heart Journal, vol. 35, no. 42, pp. 2950-2959, 2014.
[32] K. S. Reddy, "Cardiovascular disease in non-Western countries," The New England Journal of Medicine, vol. 350, no. 24, pp. 24382440, 2004.

[33] J. A. Finegold, P. Asaria, and D. P. Francis, "Mortality from ischaemic heart disease by country, region, and age: statistics from World Health Organisation and United Nations," International Journal of Cardiology, vol. 168, no. 2, pp. 934-945, 2013.

[34] K. Takeda and S. Akira, “TLR signaling pathways," Seminars in Immunology, vol. 16, no. 1, pp. 3-9, 2004.

[35] J. Gohda, T. Matsumura, and J.-I. Inoue, "Cutting edge: TNFRassociated factor (TRAF) 6 is essential for MyD88-dependent pathway but not Toll/IL-1 receptor domain-containing adaptorinducing IFN- $\beta$ (TRIF)-dependent pathway in TLR signaling," Journal of Immunology, vol. 173, no. 5, pp. 2913-2917, 2004.

[36] M. Muzio, J. Ni, P. Feng, and V. M. Dixit, "IRAK (Pelle) family member IRAK-2 and MyD88 as proximal mediators of IL-1 signaling," Science, vol. 278, no. 5343, pp. 1612-1615, 1997.

[37] Z. J. Chen, "Ubiquitin signalling in the NF- $\kappa$ B pathway," Nature Cell Biology, vol. 7, no. 8, pp. 758-765, 2005.

[38] C. Wang, L. Deng, M. Hong, G. R. Akkaraju, J.-I. Inoue, and Z. J. Chen, "TAK1 is a ubiquitin-dependent kinase of MKK and IKK," Nature, vol. 412, no. 6844, pp. 346-351, 2001.

[39] S. Ghosh, M. J. May, and E. B. Kopp, "NF- $\kappa$ B and rel proteins: evolutionarily conserved mediators of immune responses," Annual Review of Immunology, vol. 16, pp. 225-260, 1998.

[40] T. Kawasaki and T. Kawai, “Toll-like receptor signaling pathways," Frontiers in Immunology, vol. 5, article 461, 2014.

[41] M. Yamamoto, S. Sato, H. Hemmi et al., "Role of adaptor TRIF in the MyD88-independent toll-like receptor signaling pathway," Science, vol. 301, no. 5633, pp. 640-643, 2003.

[42] S. Uematsu and S. Akira, "Toll-like receptors and type I Interferons," The Journal of Biological Chemistry, vol. 282, no. 21, pp. 15319-15324, 2007.

[43] S. J. Noppert, K. A. Fitzgerald, and P. J. Hertzog, "The role of type I interferons in TLR responses," Immunology and Cell Biology, vol. 85, no. 6, pp. 446-457, 2007.

[44] C. Wang, T. Chen, J. Zhang et al., "The E3 ubiquitin ligase Nrdp1 'preferentially' promotes TLR-mediated production of type I interferon," Nature Immunology, vol. 10, no. 7, pp. 744-752, 2009.

[45] X. Liu, Z. Zhan, D. Li et al., "Intracellular MHC class II molecules promote TLR-triggered innate immune responses by maintaining activation of the kinase Btk," Nature Immunology, vol. 12, no. 5, pp. 416-424, 2011.

[46] A. O. Aliprantis, R.-B. Yang, M. R. Mark et al., "Cell activation and apoptosis by bacterial lipoproteins through Toll- like receptor-2," Science, vol. 285, no. 5428, pp. 736-739, 1999.

[47] A. O. Aliprantis, R.-B. Yang, D. S. Weiss, P. Godowski, and A. Zychlinsky, "The apoptotic signaling pathway activated by Tolllike receptor-2," The EMBO Journal, vol. 19, no. 13, pp. 3325$3336,2000$.

[48] A. Ashkenazi and V. M. Dixit, "Death receptors: signaling and modulation," Science, vol. 281, no. 5381, pp. 1305-1308, 1998.

[49] L. Yu, L. Wang, and S. Chen, "Endogenous toll-like receptor ligands and their biological significance," Journal of Cellular and Molecular Medicine, vol. 14, no. 11, pp. 2592-2603, 2010.

[50] A. M. Piccinini and K. S. Midwood, "DAMPening inflammation by modulating TLR signalling," Mediators of Inflammation, vol. 2010, Article ID 672395, 21 pages, 2010.

[51] Y. Okamura, M. Watari, E. S. Jerud et al., "The extra domain A of fibronectin activates toll-like receptor 4," The Journal of Biological Chemistry, vol. 276, no. 13, pp. 10229-10233, 2001. 
[52] S. T. Smiley, J. A. King, and W. W. Hancock, "Fibrinogen stimulates macrophage chemokine secretion through toll-like receptor 4," Journal of Immunology, vol. 167, no. 5, pp. 28872894, 2001.

[53] K. R. Taylor, K. Yamasaki, K. A. Radek et al., "Recognition of hyaluronan released in sterile injury involves a unique receptor complex dependent on toll-like receptor 4, CD44, and MD-2," The Journal of Biological Chemistry, vol. 282, no. 25, pp. 1826518275, 2007.

[54] R. M. Vabulas, P. Ahmad-Nejad, C. Da Costa et al., "Endocytosed HSP60s use toll-like receptor 2 (TLR2) and TLR4 to activate the toll/interleukin-1 receptor signaling pathway in innate immune cells," Journal of Biological Chemistry, vol. 276, no. 33, pp. 31332-31339, 2001.

[55] Y. S. Bae, J. H. Lee, S. H. Choi et al., "Macrophages generate reactive oxygen species in response to minimally oxidized lowdensity lipoprotein: toll-like receptor 4 - and spleen tyrosine kinase-dependent activation of NADPH oxidase 2," Circulation Research, vol. 104, no. 2, pp. 210-218, 2009.

[56] K. Ohashi, V. Burkart, S. Flohé, and H. Kolb, "Cutting edge: heat shock protein 60 is a putative endogenous ligand of the toll-like receptor-4 complex," Journal of Immunology, vol. 164, no. 2, pp. 558-561, 2000.

[57] Y. Bulut, E. Faure, L. Thomas et al., "Chlamydial heat shock protein 60 activates macrophages and endothelial cells through toll-like receptor 4 and MD2 in a MyD88-dependent pathway," The Journal of Immunology, vol. 168, no. 3, pp. 1435-1440, 2002.

[58] C. U. Prazeres da Costa, N. Wantia, C. J. Kirschning et al., "Heat shock protein 60 from Chlamydia pneumoniae elicits an unusual set of imflammatory responses via Tol-like receptor 2 and 4 in vivo," European Journal of Immunology, vol. 34, no. 10, pp. 2874-2884, 2004.

[59] B. Gao and M.-F. Tsan, "Endotoxin contamination in recombinant human heat shock protein 70 (Hsp70) preparation is responsible for the induction of tumor necrosis factor $\alpha$ release by murine macrophages," The Journal of Biological Chemistry, vol. 278, no. 1, pp. 174-179, 2003.

[60] M.-F. Tsan and B. Gao, "Endogenous ligands of Toll-like receptors," Journal of Leukocyte Biology, vol. 76, no. 3, pp. 514$519,2004$.

[61] U. Zähringer, B. Lindner, S. Inamura, H. Heine, and C. Alexander, "TLR2-promiscuous or specific? A critical reevaluation of a receptor expressing apparent broad specificity," Immunobiology, vol. 213, no. 3-4, pp. 205-224, 2008.

[62] T. H. Flo, Ø. Halaas, S. Torp et al., "Differential expression of toll-like receptor 2 in human cells," Journal of Leukocyte Biology, vol. 69 , no. 3, pp. 474-481, 2001.

[63] L. Oliveira-Nascimento, P. Massari, and L. M. Wetzler, "The role of TLR2 in infection and immunity," Frontiers in Immunology, vol. 3, article 79, 2012.

[64] K. Edfeldt, J. Swedenborg, G. K. Hansson, and Z.-Q. Yan, "Expression of toll-like receptors in human atherosclerotic lesions: a possible pathway for plaque activation," Circulation, vol. 105, no. 10, pp. 1158-1161, 2002.

[65] S. Dunzendorfer, H.-K. Lee, and P. S. Tobias, "Flow-dependent regulation of endothelial toll-like receptor 2 expression through inhibition of SP1 activity," Circulation Research, vol. 95, no. 7, pp. 684-691, 2004.

[66] A. E. Mullick, P. S. Tobias, and L. K. Curtiss, "Modulation of atherosclerosis in mice by Toll-like receptor 2," The Journal of Clinical Investigation, vol. 115, no. 11, pp. 3149-3156, 2005.
[67] A. E. Mullick, K. Soldau, W. B. Kiosses, T. A. Bell III, P. S. Tobias, and L. K. Curtiss, "Increased endothelial expression of Tolllike receptor 2 at sites of disturbed blood flow exacerbates early atherogenic events," Journal of Experimental Medicine, vol. 205, no. 2, pp. 373-383, 2008.

[68] A. H. Schoneveld, M. M. Oude Nijhuis, B. Van Middelaar, J. D. Laman, D. P. V. De Kleijn, and G. Pasterkamp, "Tolllike receptor 2 stimulation induces intimal hyperplasia and atherosclerotic lesion development," Cardiovascular Research, vol. 66, no. 1, pp. 162-169, 2005.

[69] G.-L. Lee, Y.-W. Chang, J.-Y. Wu et al., "TLR 2 induces vascular smooth muscle cell migration through cAMP response element-binding protein-mediated interleukin-6 production," Arteriosclerosis, Thrombosis, and Vascular Biology, vol. 32, no. 11, pp. 2751-2760, 2012.

[70] M. Madan and S. Amar, "Toll-like receptor-2 mediates diet and/or pathogen associated atherosclerosis: proteomic findings," PLoS ONE, vol. 3, no. 9, Article ID e3204, 2008.

[71] T. Shishido, N. Nozaki, H. Takahashi et al., "Central role of endogenous Toll-like receptor-2 activation in regulating inflammation, reactive oxygen species production, and subsequent neointimal formation after vascular injury," Biochemical and Biophysical Research Communications, vol. 345, no. 4, pp. 14461453,2006

[72] J. Favre, P. Musette, V. Douin-Echinard et al., "Toll-like receptors 2-deficient mice are protected against postischemic coronary endothelial dysfunction," Arteriosclerosis, Thrombosis, and Vascular Biology, vol. 27, no. 5, pp. 1064-1071, 2007.

[73] L. Chávez-Sánchez, M. G. Garza-Reyes, J. E. Espinosa-Luna, K. Chávez-Rueda, M. V. Legorreta-Haquet, and F. Blanco-Favela, "The role of TLR2, TLR4 and CD36 in macrophage activation and foam cell formation in response to oxLDL in humans," Human Immunology, vol. 75, no. 4, pp. 322-329, 2014.

[74] K. Inoue, K.-I. Kawahara, K. K. Biswas et al., "HMGB1 expression by activated vascular smooth muscle cells in advanced human atherosclerosis plaques," Cardiovascular Pathology, vol. 16, no. 3, pp. 136-143, 2007.

[75] D. Messmer, H. Yang, G. Telusma et al., "High mobility group box protein 1: an endogenous signal for dendritic cell maturation and Thl polarization," The Journal of Immunology, vol. 173, no. 1, pp. 307-313, 2004.

[76] M. A. Christman II, D. J. Goetz, E. Dickerson et al., "Wnt5a is expressed in murine and human atherosclerotic lesions," American Journal of Physiology-Heart and Circulatory Physiology, vol. 294, no. 6, pp. H2864-H2870, 2008.

[77] P. M. Bhatt, C. J. Lewis, D. L. House et al., "Increased Wnt5a mRNA expression in advanced atherosclerotic lesions, and oxidized LDL treated human monocyte-derived macrophages," The Open Circulation and Vascular Journal, vol. 5, no. 1, pp. 1-7, 2012.

[78] L. Qin, R. Hu, N. Zhu et al., "The novel role and underlying mechanism of Wnt5a in regulating cellular cholesterol accumulation," Clinical and Experimental Pharmacology and Physiology, vol. 41, no. 9, pp. 671-678, 2014.

[79] I. Ackers, C. Szymanski, K. J. Duckett, K. McCall, and R. Malgor, "Wnt5a signaling in atherosclerosis, its effect on OxLDL uptake and foam cell differentiation," The FASEB Journal, vol. 29, supplement 1, p. 609.4, 2015.

[80] P. M. Bhatt and R. Malgor, "Wnt5a: a player in the pathogenesis of atherosclerosis and other inflammatory disorders," Atherosclerosis, vol. 237, no. 1, pp. 155-162, 2014. 
[81] N. J. Gay, M. F. Symmons, M. Gangloff, and C. E. Bryant, "Assembly and localization of Toll-like receptor signalling complexes," Nature Reviews Immunology, vol. 14, no. 8, pp. 546$558,2014$.

[82] H. Methe, J.-O. Kim, S. Kofler, M. Weis, M. Nabauer, and J. Koglin, "Expansion of circulating toll-like receptor 4-positive monocytes in patients with acute coronary syndrome," Circulation, vol. 111, no. 20, pp. 2654-2661, 2005.

[83] H.-L. Geng, H.-Q. Lu, L.-Z. Zhang et al., "Increased expression of Toll like receptor 4 on peripheral-blood mononuclear cells in patients with coronary arteriosclerosis disease," Clinical and Experimental Immunology, vol. 143, no. 2, pp. 269-273, 2006.

[84] M. Satoh, Y. Shimoda, C. Maesawa et al., "Activated toll-like receptor 4 in monocytes is associated with heart failure after acute myocardial infarction," International Journal of Cardiology, vol. 109, no. 2, pp. 226-234, 2006.

[85] L. D. Tapp, E. Shantsila, B. J. Wrigley, S. Montoro-Garcia, and G. Y. H. Lip, "TLR4 expression on monocyte subsets in myocardial infarction," Journal of Internal Medicine, vol. 273, no. 3, pp. 294305, 2013.

[86] K. W. Howell, X. Meng, D. A. Fullerton, C. Jin, T. B. Reece, and J. C. Cleveland Jr., "Toll-like receptor 4 mediates oxidized LDLinduced macrophage differentiation to foam cells," Journal of Surgical Research, vol. 171, no. 1, pp. e27-e31, 2011.

[87] K. Yang, X. J. Zhang, L. J. Cao et al., “Toll-like receptor 4 mediates inflammatory cytokine secretion in smooth muscle cells induced by oxidized low-density lipoprotein," PLOS ONE, vol. 9, no. 4, Article ID e95935, 2014.

[88] Y. I. Miller, S. Viriyakosol, C. J. Binder, J. R. Feramisco, T. N. Kirkland, and J. L. Witztum, "Minimally modified LDL binds to CD14, induces macrophage spreading via TLR4/MD2, and inhibits phagocytosis of apoptotic cells," The Journal of Biological Chemistry, vol. 278, no. 3, pp. 1561-1568, 2003.

[89] S.-H. Choi, R. Harkewicz, J. H. Lee et al., "Lipoprotein accumulation in macrophages via toll-like receptor-4-dependent fluid phase uptake," Circulation Research, vol. 104, no. 12, pp. 13551363, 2009.

[90] Y. I. Miller, S.-H. Choi, P. Wiesner, and Y. S. Bae, “The SYK side of TLR4: signalling mechanisms in response to LPS and minimally oxidized LDL," British Journal of Pharmacology, vol. 167, no. 5, pp. 990-999, 2012.

[91] H. Björkbacka, V. V. Kunjathoor, K. J. Moore et al., "Reduced atherosclerosis in MyD88-null mice links elevated serum cholesterol levels to activation of innate immunity signaling pathways," Nature Medicine, vol. 10, no. 4, pp. 416-421, 2004.

[92] K. S. Michelsen, M. H. Wong, P. K. Shah et al., "Lack of tolllike receptor 4 or myeloid differentiation factor 88 reduces atherosclerosis and alters plaque phenotype in mice deficient in apolipoprotein E," Proceedings of the National Academy of Sciences of the United States of America, vol. 101, no. 29, pp. 10679-10684, 2004.

[93] M. Higashimori, J. B. Tatro, K. J. Moore, M. E. Mendelsohn, J. B. Galper, and D. Beasley, "Role of toll-like receptor 4 in intimal foam cell accumulation in apolipoprotein E-deficient mice," Arteriosclerosis, Thrombosis, and Vascular Biology, vol. 31, no. 1, pp. 50-57, 2011.

[94] K. R. Coenen, M. L. Gruen, R. S. Lee-Young, M. J. Puglisi, D. H. Wasserman, and A. H. Hasty, "Impact of macrophage toll-like receptor 4 deficiency on macrophage infiltration into adipose tissue and the artery wall in mice," Diabetologia, vol. 52, no. 2 , pp. 318-328, 2009.
[95] G. Pasterkamp, A. H. Schoneveld, D. J. Hijnen et al., "Atherosclerotic arterial remodeling and the localization of macrophages and matrix metalloproteases 1, 2 and 9 in the human coronary artery," Atherosclerosis, vol. 150, no. 2, pp. 245-253, 2000.

[96] S. C. G. Hollestelle, M. R. De Vries, J. K. Van Keulen et al., "Toll-like receptor 4 is involved in outward arterial remodeling," Circulation, vol. 109, no. 3, pp. 393-398, 2004.

[97] Y. Ishikawa, M. Satoh, T. Itoh, Y. Minami, Y. Takahashi, and M. Akamura, "Local expression of Toll-like receptor 4 at the site of ruptured plaques in patients with acute myocardial infarction," Clinical Science, vol. 115, no. 3-4, pp. 133-140, 2008.

[98] S. Gargiulo, P. Gamba, G. Testa et al., "Relation between TLR4/NF- $\kappa \mathrm{B}$ signaling pathway activation by 27hydroxycholesterol and 4-hydroxynonenal, and atherosclerotic plaque instability," Aging Cell, vol. 14, no. 4, pp. 569-581, 2015.

[99] E. W. Raines, "The extracellular matrix can regulate vascular cell migration, proliferation, and survival: relationships to vascular disease," International Journal of Experimental Pathology, vol. 81, no. 3, pp. 173-182, 2000.

[100] A. W. Orr, J. M. Sanders, M. Bevard, E. Coleman, I. J. Sarembock, and M. A. Schwartz, "The subendothelial extracellular matrix modulates NF- $\kappa \mathrm{B}$ activation by flow: a potential role in atherosclerosis," The Journal of Cell Biology, vol. 169, no. 1, pp. 191-202, 2005.

[101] B. V. Shekhonin, S. P. Domogatsky, G. L. Idelson, V. E. Koteliansky, and V. S. Rukosuev, "Relative distribution of fibronectin and type I, III, IV, V collagens in normal and atherosclerotic intima of human arteries," Atherosclerosis, vol. 67, no. 1, pp. 9-16, 1987.

[102] E. S. White, F. E. Baralle, and A. F. Muro, "New insights into form and function of fibronectin splice variants," Journal of Pathology, vol. 216, no. 1, pp. 1-14, 2008.

[103] M. H. Tan, Z. Sun, S. L. Opitz, T. E. Schmidt, J. H. Peters, and E. L. George, "Deletion of the alternatively spliced fibronectin EIIIA domain in mice reduces atherosclerosis," Blood, vol. 104, no. 1, pp. 11-18, 2004.

[104] V. R. Babaev, F. Porro, M. F. Linton, S. Fazio, F. E. Baralle, and A. F. Muro, "Absence of regulated splicing of fibronectin EDA exon reduces atherosclerosis in mice," Atherosclerosis, vol. 197, no. 2, pp. 534-540, 2008.

[105] P. Doddapattar, C. Gandhi, P. Prakash et al., "Fibronectin splicing variants containing extra domain A promote atherosclerosis in mice through Toll-like receptor 4," Arteriosclerosis, Thrombosis, and Vascular Biology, vol. 35, no. 11, pp. 2391-2400, 2015.

[106] P. Prakash, P. P. Kulkarni, S. R. Lentz, and A. K. Chauhan, "Cellular fibronectin containing extra domain A promotes arterial thrombosis in mice through platelet Toll-like receptor 4," Blood, vol. 125, no. 20, pp. 3164-3172, 2015.

[107] H. Hemmi, O. Takeuchi, T. Kawai et al., "A Toll-like receptor recognizes bacterial DNA," Nature, vol. 408, no. 6813, pp. 740745, 2000.

[108] A. Dalpke, J. Frank, M. Peter, and K. Heeg, "Activation of toll-like receptor 9 by DNA from different bacterial species," Infection and Immunity, vol. 74, no. 2, pp. 940-946, 2006.

[109] R. Sorrentino, S. Morello, S. Chen, E. Bonavita, and A. Pinto, "The activation of liver X receptors inhibits toll-like receptor9-induced foam cell formation," Journal of Cellular Physiology, vol. 223, no. 1, pp. 158-167, 2010.

[110] M. Baranowski, "Biological role of liver X receptors," Journal of Physiology and Pharmacology, vol. 59, supplement 7, pp. 31-55, 2008. 
[111] A. Niessner, K. Sato, E. L. Chaikof, I. Colmegna, J. J. Goronzy, and C. M. Weyand, "Pathogen-sensing plasmacytoid dendritic cells stimulate cytotoxic T-cell function in the atherosclerotic plaque through interferon- $\alpha$," Circulation, vol. 114, no. 23, pp. 2482-2489, 2006.

[112] J.-D. Bouaziz, S. Calbo, M. Maho-Vaillant et al., "IL-10 produced by activated human $\mathrm{B}$ cells regulates $\mathrm{CD} 4^{+} \mathrm{T}$-cell activation in vitro," European Journal of Immunology, vol. 40, no. 10, pp. 2686-2691, 2010.

[113] Z. Waibler, M. Anzaghe, A. Konur, S. Akira, W. Müller, and U. Kalinke, "Excessive CpG 1668 stimulation triggers IL-10 production by cDC that inhibits IFN- $\alpha$ responses by pDC," European Journal of Immunology, vol. 38, no. 11, pp. 3127-3137, 2008.

[114] C. Koulis, Y.-C. Chen, C. Hausding et al., "Protective role for toll-like receptor-9 in the development of atherosclerosis in apolipoprotein E-deficient mice," Arteriosclerosis, Thrombosis, and Vascular Biology, vol. 34, no. 3, pp. 516-525, 2014.

[115] C. Ma, Q. Ouyang, Z. Huang et al., "Toll-like receptor 9 inactivation alleviated atherosclerotic progression and inhibited macrophage polarized to M1 phenotype in $\mathrm{ApoE}^{-/-}$mice," Disease Markers, vol. 2015, Article ID 909572, 9 pages, 2015.

[116] A. O. Krogmann, E. Lüsebrink, M. Steinmetz et al., "Proinflammatory stimulation of toll-like receptor 9 with high dose CpG ODN 1826 impairs endothelial regeneration and promotes atherosclerosis in mice," PLoS ONE, vol. 11, no. 1, article e0146326, 2016.

[117] H. Ait-Oufella, B. L. Salomon, S. Potteaux et al., "Natural regulatory $\mathrm{T}$ cells control the development of atherosclerosis in mice," Nature Medicine, vol. 12, no. 2, pp. 178-180, 2006.

[118] C. Buono, C. J. Binder, G. Stavrakis, J. L. Witztum, L. H. Glimcher, and A. H. Lichtman, "T-bet deficiency reduces atherosclerosis and alters plaque antigen-specific immune responses," Proceedings of the National Academy of Sciences of the United States of America, vol. 102, no. 5, pp. 1596-1601, 2005.

[119] K. Tse, H. Tse, J. Sidney, A. Sette, and K. Ley, "T cells in atherosclerosis," International Immunology, vol. 25, no. 11, pp. 615-622, 2013.

[120] A. C. Foks, A. H. Lichtman, and J. Kuiper, "Treating atherosclerosis with regulatory T cells," Arteriosclerosis, Thrombosis, and Vascular Biology, vol. 35, no. 2, pp. 280-287, 2015.

[121] M. Subramanian, E. Thorp, G. K. Hansson, and I. Tabas, "Treg-mediated suppression of atherosclerosis requires MYD88 signaling in DCs," The Journal of Clinical Investigation, vol. 123, no. 1, pp. 179-188, 2013.

[122] B. Hou, B. Reizis, and A. L. DeFranco, "Toll-like receptors activate innate and adaptive immunity by using dendritic cellintrinsic and -extrinsic mechanisms," Immunity, vol. 29, no. 2, pp. 272-282, 2008.

[123] G. K. Hansson and J. Nilsson, "Vaccination against atherosclerosis? Induction of atheroprotective immunity," Seminars in Immunopathology, vol. 31, no. 1, pp. 95-101, 2009.

[124] S. Kiechl, E. Lorenz, M. Reindl et al., "Toll-like receptor 4 polymorphisms and atherogenesis," The New England Journal of Medicine, vol. 347, no. 3, pp. 185-192, 2002.

[125] R. Labrum, S. Bevan, M. Sitzer, M. Lorenz, and H. S. Markus, "Toll receptor polymorphisms and carotid artery intima-media thickness," Stroke, vol. 38, no. 4, pp. 1179-1184, 2007.

[126] N. Ameziane, T. Beillat, P. Verpillat et al., "Association of the Toll-like receptor 4 gene Asp299Gly polymorphism with acute coronary events," Arteriosclerosis, Thrombosis, and Vascular Biology, vol. 23, no. 12, pp. e61-e64, 2003.
[127] S. M. Boekholdt, W. R. P. Agema, R. J. G. Peters et al., "Variants of toll-like receptor 4 modify the efficacy of statin therapy and the risk of cardiovascular events," Circulation, vol. 107, no. 19, pp. 2416-2421, 2003.

[128] W. Koch, P. Hoppmann, A. Pfeufer, A. Schömig, and A. Kastrati, "Toll-like receptor 4 gene polymorphisms and myocardial infarction: no association in a Caucasian population," European Heart Journal, vol. 27, no. 21, pp. 2524-2529, 2006.

[129] A. G. Kutikhin, A. V. Ponasenko, M. V. Khutornaya et al., "Association of TLR and TREM-1 gene polymorphisms with atherosclerosis severity in a Russian population," Meta Gene, vol. 9, pp. 76-89, 2016.

[130] T. Tahara, T. Arisawa, T. Shibata, I. Hirata, and H. Nakano, "Absence of common polymorphisms of toll like receptor 4 (TLR4): Asp299Gly, Thr399Ile in patients with gastroduodenal diseases in Japan," Journal of Clinical Biochemistry and Nutrition, vol. 40, no. 1, pp. 62-65, 2007. 


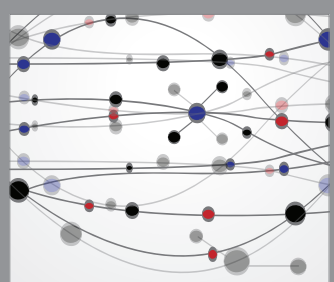

The Scientific World Journal
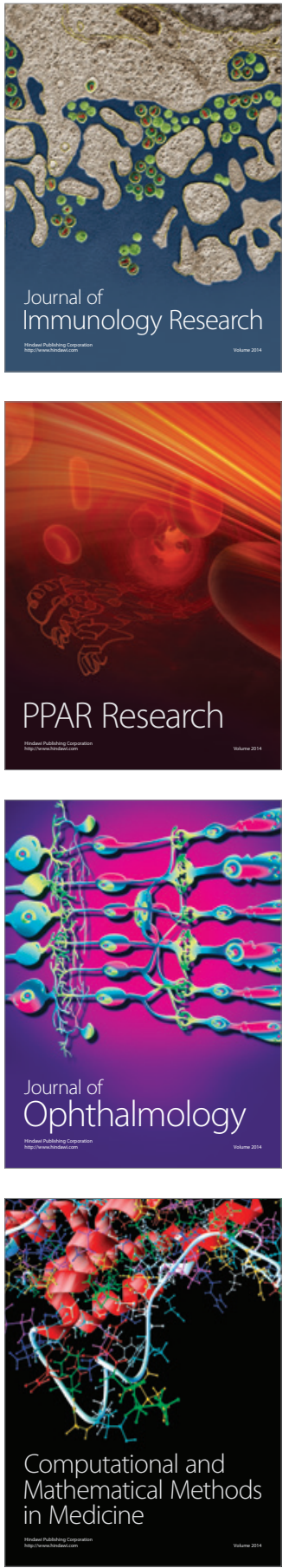

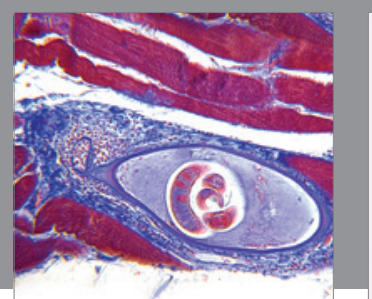

Gastroenterology Research and Practice

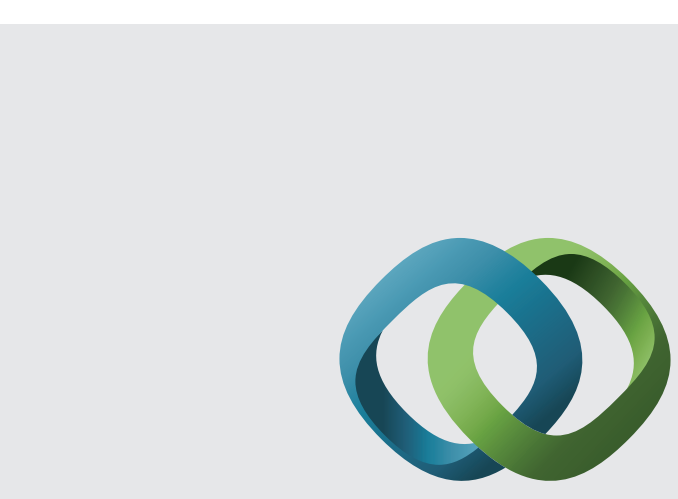

\section{Hindawi}

Submit your manuscripts at

http://www.hindawi.com
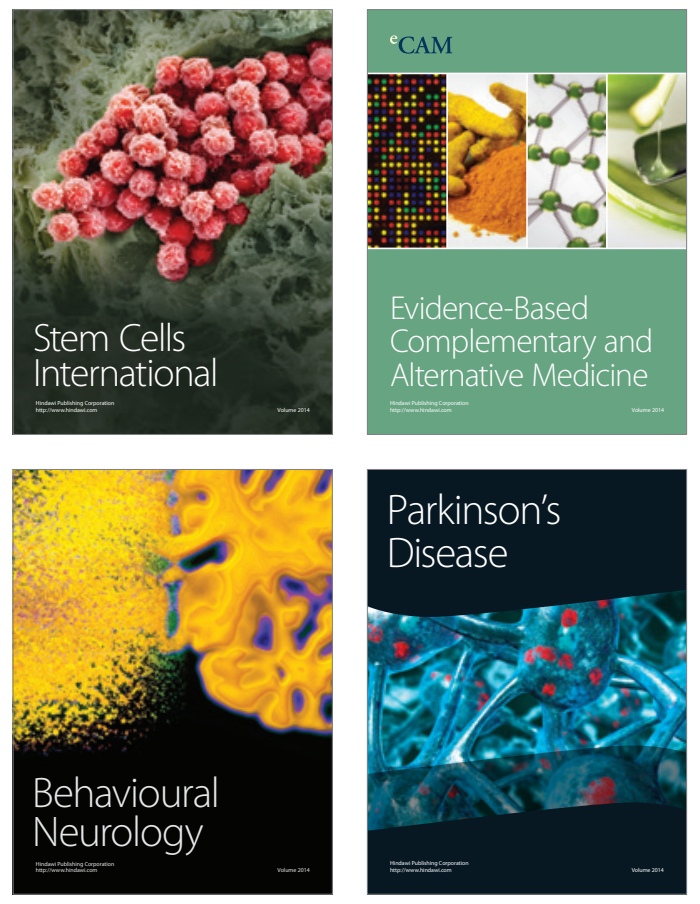
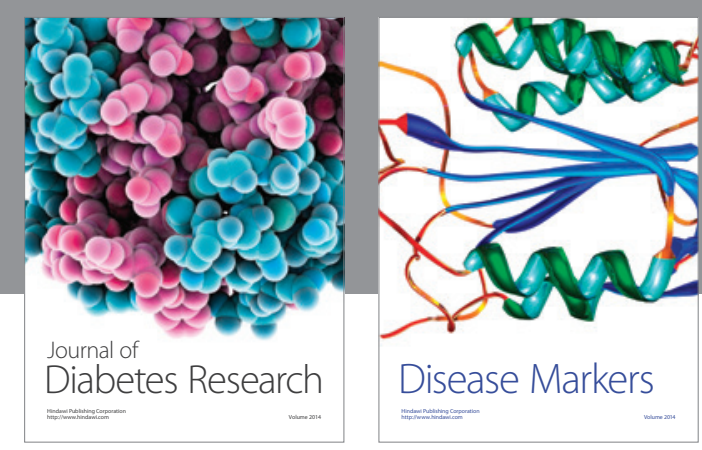

Disease Markers
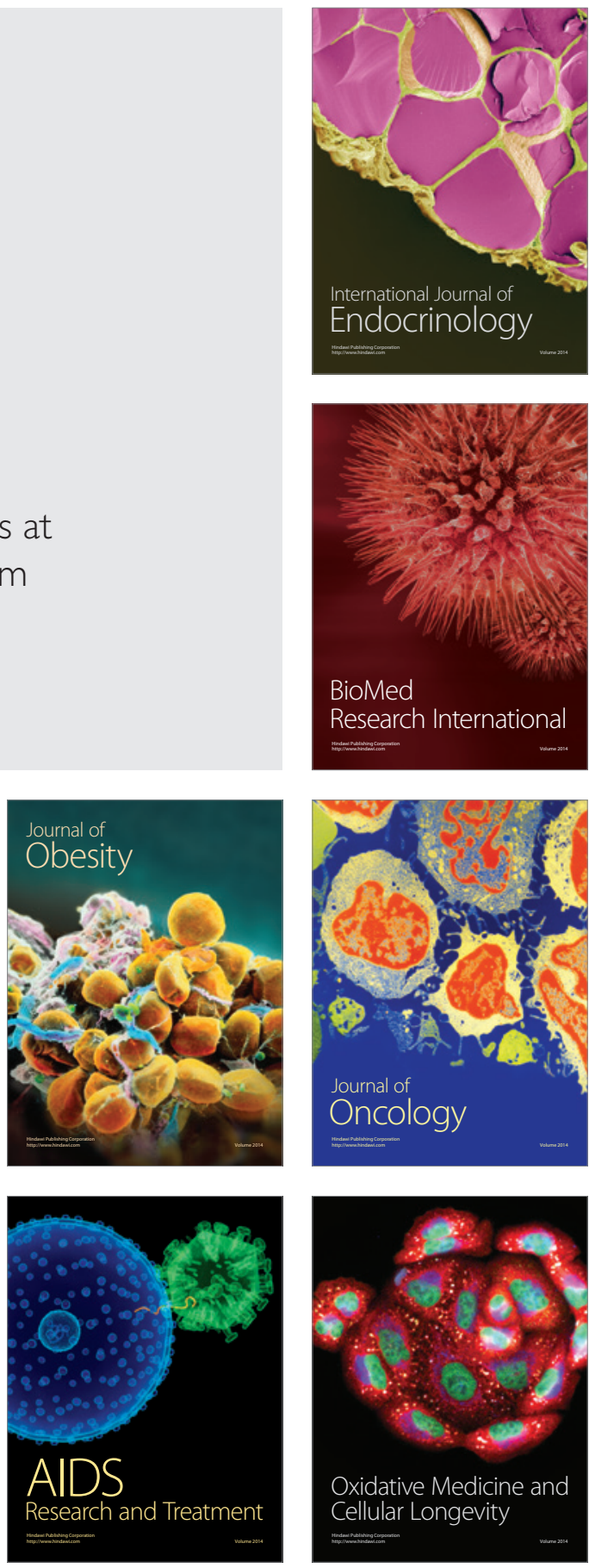